\title{
Aporte sobre un polémico episodio en la historia de las quinas
}

\section{A contribution on a controversial episode in the history of the quinas}

\author{
Nicolás Cuvi ${ }^{i}$ \\ i Profesor investigador, Departamento de Antropología, Historia y Humanidades/Flacso Ecuador. \\ Quito - Ecuador \\ orcid.org/0000-0002-3206-5672 \\ ncuvi@flacso.edu.ec
}

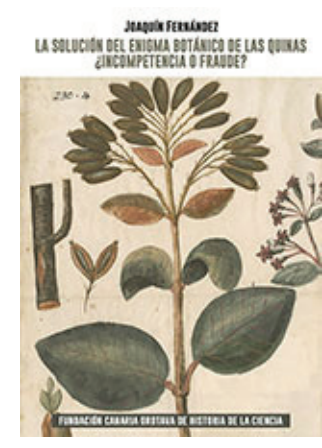

FERNÁNDEZ, Joaquín. La solución del enigma botánico de las quinas. ¿Incompetencia o fraude? La Orotava: Fundación Canaria Orotava de Historia de la Ciencia, 2019. 154p.
En historia de la ciencia, es difícil hacer aportes originales sobre temas muy analizados. Es el caso de la historia de las quinas, Cinchona spp., plantas medicinales sobre las cuales se han escrito miles de documentos. Si se hace una búsqueda en Google Scholar usando los términos "historia + Cinchona", aparecen cerca de cinco mil documentos. En inglés son más de treinta mil, y, en francés, más de dos mil referencias.

Una consecuencia de tal profusión de trabajos ha sido una enorme cantidad de confusiones, malas interpretaciones, rectificaciones, entre otros. Por eso, puede ser difícil hilar la historia de las exploraciones, de las prácticas médicas, de actores, de cuestiones comerciales, y otros temas de la historia de esas plantas. Cuando nos aventuramos en el tema, tras leer algunos artículos y libros, creemos estar en conocimiento de los asuntos más importantes, pero pronto encontramos nuevas fuentes, primarias y secundarias, que refutan las interpretaciones y explicaciones previas. Un clásico en esa línea es el trabajo de Haggis (1941), que contribuyó con análisis decisivos para cuestionar definitivamente el mito de la Condesa de Chinchón, asociado con la planta. De ese modo, la historia de las quinas puede suscitar desesperados sentimientos de extravío entre los historiadores, casi tantos como los que enfrentan los taxónomos por el alto grado de hibridación de esas plantas.

Ante la profundidad y complejidad histórica e historiográfica de las quinas, el breve libro de Joaquín Fernández (2019) es un buen aporte, pues sintetiza varios temas, precisa ciertas polémicas historiográficas y, además, presenta una provocadora interpretación de un episodio particular: el silencio de José Celestino Mutis y de otros naturalistas a principios del siglo XIX en torno a las precisas observaciones taxonómicas y biogeográficas realizadas por el payanés Francisco José de Caldas. 
A partir de una bien escogida selección de fuentes, el autor ilustra las dificultades que conllevó, desde el siglo XVIII, la identificación de las especies de quinas, cuando sus alcaloides medicinales se volvieron productos cada vez más apetecidos. Explica aspectos de los trabajos de Charles Marie de la Condamine, Miguel de Santistevan y otros personajes, pero el foco principal está en los trabajos de Caldas, quien proveyó la información más precisa sobre la taxonomía.

El neogranadino hizo sus aportes en un contexto en el que confluían intereses de comerciantes en Nueva Granada, Perú y Europa, que querían que las quinas de sus territorios fuesen consideradas como las de mayor calidad. Había muchas adulteraciones y envíos de cortezas de especies con pocos alcaloides medicinales. El referente era la llamada "quina fina" o "quina verdadera", la Cinchona officinalis, endémica de la región de Loja, aunque varias partes interesadas, entre los cuales Mutis, sostenían que su distribución era mayor. Caldas, sin embargo, fue claro en 1805 al desmentir esas aspiraciones, asunto que no fue recogido ni por el gaditano ni por otros ilustres naturalistas de la época. Ya en el título del libro, Fernández se pregunta si aquello fue incompetencia o fraude, aunque en sus textos queda claro que se inclina por cuestionar el sospechoso silencio sistemático que hubo para no afectar intereses comerciales. Es explícito al decir que el enigma de las quinas fue resuelto hace 200 años, pero nadie quiso aceptarlo.

El lenguaje de libro es llano y directo, haciéndolo accesible a públicos no especialistas. Además de una introducción y conclusiones, cuenta con diez breves secciones que, por su tamaño, no pueden ser llamadas capítulos. Cada sección arranca con una cita histórica que adelanta el contenido. La primera contiene una cita del informe de Miguel de Santistevan de 1753 y varios antecedentes sobre la búsqueda de quinas en la primera mitad del siglo XVIII. La segunda, muy breve, comienza con el fragmento de una carta de Linneo a Mutis y desarrolla partes de la relación entre ambos naturalistas. Un informe de Mutis al Virrey abre la tercera sección; introduce a los intereses comerciales del gaditano y sus polémicas con personajes como Sebastián López Ruiz. La cuarta sección arranca con una cita de Hipólito Ruiz de 1780 y se detiene en la disputa entre las dos expediciones botánicas a la América Meridional. La quinta sección se ocupa de los intereses de la Corona española por un estanco, los problemas por las falsificaciones de cortezas y el fracaso comercial de Mutis. La sexta sección, inaugurada con una cita del mismo gaditano, introduce la polémica taxonómica asociada con los intereses comerciales. Finalmente, entre las secciones séptima y décima se presenta el contenido más original del libro: los estudios de Caldas y el silencio que se mantuvo ante ellos.

Se incluyen tres documentos como anexos: el informe de Miguel de Santistevan de 1753, la más difundida Memoria sobre las quinas de Caldas de 1805, y el menos conocido documento de análisis de esa memoria, realizado en 1808 por Gregorio Bañares.

Al final del trabajo, el autor ha insertado un post scriptum en el que detalla algunas dificultades que tuvo para difundir su trabajo tanto en España como en Colombia. Especula que quizás aquello respondió a que sus argumentos comprometen la imagen, bastante hagiográfica, que ha sido construida sobre Mutis. En ese sentido, su trabajo se sitúa en la línea de otros ensayos críticos sobre ese naturalista como el libro Remedios para el imperio: historia natural y la apropriación del Nuevo Mundo (Nieto Olarte, 2006). Sus argumentos 
provocadores y bien fundamentados son una razón para considerarlo en los debates amplios sobre historia de la ciencia y, de modo particular, sobre los expedicionarios europeos en América.

\section{REFERENCIAS}

FERNÁNDEZ, Joaquín. La solución del enigma botánico de las quinas ¿Incompetencia o fraude? La Orotava: Fundación Canaria Orotava de Historia de la Ciencia, 2019.

HAGGIS, A.W. Fundamental errors in the early history of Cinchona: Part I. Bulletin of the History of Medicine, v.10, n.3, p.417-459,
1941. Disponible en: <https://www.jstor.org/ stable/44446253>. Acceso en: 9 jan. 2021.

NIETO OLARTE, Mauricio. Remedios para el imperio: historia natural y la apropiación del Nuevo Mundo. Bogotá: Universidad de los Andes, 2006.

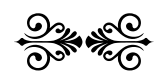

